\title{
APROPRIAÇÕES DE FILMES E VÍDEOS NA EDUCAÇÃO MÉDICA
}

\author{
MOVIE AND VIDEO APROPRIATION IN MEDICAL EDUCATION
}

\author{
Américo de Araujo Pastor Junior ${ }^{1}$ \\ Luiz Augusto Coímbra de Rezende Filho ${ }^{2}$ \\ Marcus Vinícius Pereira ${ }^{3}$ \\ Wagner Gonçalves Bastos ${ }^{4}$
}

\section{Resumo}

A educação tem se apropriado de filmes e vídeos segundo concepções nem sempre problematizadas dessas mídias, que por usa vez guiam os modos como elas serão utilizadas em sala de aula. Considerando o recente crescimento do número de estudos sobre vídeos e filmes na área de Educação Médica nos últimos anos, torna-se relevante caracterizar essa produção e identificar que concepções norteiam essas apropriações. Diante disso, apresentamos uma revisão de literatura dos últimos dez anos de produções em periódicos, que revelou a carência de pressupostos embasados em resultados de pesquisa, uma vez que tanto os estudos teóricos quanto os empíricos conferem aos audiovisuais potenciais e vantagens que necessitam ser mais bem estudados.

Palavras-chave: revisão de literatura. educação médica. recursos audiovisuais.

\begin{abstract}
Film and video have been appropriated in education filed according conceptions not always problematized about these media, on the other hand they define the ways in which media will be used in the classroom. Considering that in recent years the number of studies have increased on Medical Education area about videos and movies, it is relevant to characterize this production and identify which conceptions guide these appropriations. Therefore, we present a ten years literature review, which revealed the lack of assumptions grounded in research results, since both theoretical and empirical studies give to audiovisual potential and advantages that need to be more well studied.
\end{abstract}

Key-words literature review. medical education. audiovisual resources.

\footnotetext{
${ }^{1} \mathrm{O}$ autor é doutor em Educação em Ciências e Saúde pelo Núcleo de Tecnologia Educacional para a Saúde (NUTES) da Universidade Federal do Rio de Janeiro (UFRJ). E-mail: americoapj@ gmail.com

2 O autor é doutor em Comunicação, professor no Núcleo de Tecnologia Educacional para a Saúde (NUTES/UFRJ), onde atualmente coordena o Laboratório de Vídeo Educativo (LVE) e o Programa de PósGraduação Stricto Sensu em Educação em Ciências e Saúde. É bolsista Jovem Cientista do Nosso Estado da FAPERJ. E-mail: luizrezende@ufrj.br

${ }^{3} \mathrm{O}$ autor é doutor em Educação em Ciências e Saúde, professor do Instituto Federal do Rio de Janeiro (IFRJ), onde atualmente é docente permanente do Programa de Pós-graduação Stricto Sensu em Ensino de Ciências (PROPEC). E-mail: marcus.pereira@ifrj.edu.br

${ }^{4} \mathrm{O}$ autor é doutor em Educação em Ciências e Saúde, professor da Faculdade de Formação de Professores (FFP) da Universidade do Estado do Rio de Janeiro (UERJ). E-mail: wgnutes@ gmail.com
} 


\section{INTRODUÇÃO}

A Educação Médica no Brasil, nos últimos 40 anos, passou por mudanças em seus objetivos, organização, conteúdos e estratégias pedagógicas. Um dos principais motivos residiu na crítica à ênfase nos saberes biomédicos em detrimento dos saberes que tomam o homem em sua complexidade biopsicossocial. Santos e Westphal (1999) e Pagliosa e Da Ros (2008) indicam que uma formação médica tradicional tem ênfase biomédica, privilegia abordagens positivistas da ciência e se pauta em uma prática médica desumanizada que não vai além dos aspectos meramente biológicos por priorizar abordagens mecanicistas, tecnologicizadas e descontextualizadas. Para Lampert (2004), nesse modelo tradicional o processo de ensino-aprendizagem centra-se no professor e dá ênfase à memorização de conteúdos, ao raciocínio clínico e a habilidades selecionadas. Tal modelo passa a ser alvo de críticas mais intensas a partir da década de 1960 e que perduram atualmente, influenciando determinantemente currículos de muitas escolas médicas brasileiras. (ALMEIDA et al., 2007).

Em todo o mundo, diferentes respostas a essas críticas surgiram para tentar dar conta dessa formação pouco interdisciplinar, e, nesse sentido, ganharam destaque, no contexto brasileiro, as Diretrizes Curriculares Nacionais (DCN), que, para Santos e Westphal (1999), propõem a formação de profissionais que desenvolvam uma prática médica mais humanizada e centrada nas necessidades da população, com enfoque no grupo social ao qual o indivíduo pertence e não apenas no indivíduo, passando de uma ênfase curativista a preventivista. Segundo Perim et al. (2010), as DCN apontaram um novo caminho para a formação do médico, prevendo a integração de conteúdos e o desenvolvimento de competências e habilidades, valendo-se de metodologias ativas de ensino, integração entre ensino e serviços de saúde e aproximação do futuro médico à realidade social.

Em pesquisas anteriores (PASTOR JUNIOR; REZENDE; BASTOS, 2012), pudemos notar em trabalhos como Blasco et al. (2005), Klemenc-Ketis e Kersnik (2011) e Wong et al. (2009) que os vídeos e filmes foram apresentados como importantes recursos para tratar de temas relacionados à humanização da prática médica, sobretudo da relação médico-paciente (RMP). Para esses autores os filmes, ao envolverem as emoções dos alunos, dispõem de um grande potencial comunicativo para suscitar reflexões sobre suas práticas e contribuem significativamente para uma formação em busca de uma RMP mais empática. 
Na pesquisa em educação, essas ideias também se fazem presentes e se sustentam em argumentos tais como: a narrativa fílmica pode permitir a percepção crítica da sociedade (HODGE; KRESS, 1988); os vídeos podem despertar e reforçar o interesse de alunos, a curiosidade e motivação para novos temas (FERRÉS, 1996); os audiovisuais transportam fatos cotidianos para a sala de aula, que abrem um canal privilegiado de acesso aos níveis cognitivo, afetivo e da ação e aos códigos de comunicação de modo geral (ARROIO; GIORDAN, 2006).

Entretanto, tais apropriações de filmes e vídeos em contextos educativos são questionadas já há algum tempo. Em trabalho originalmente publicado em 1974, Sol Worth (1981) destacava que os usos educativos de filmes são frequentemente compreendidos através das lentes de pressupostos que não foram suficientemente investigados em pesquisas empíricas, entre eles: (1) a ideia de uma linguagem universal conferida aos filmes/vídeos (que poderiam comunicar para pessoas de diferentes culturas, idades e gêneros); (2) a suposta primazia psicológica e social que as imagens teriam sobre as palavras, por serem compreendidas como uma forma de pensamento visual (bastante comum em expressões como "uma imagem vale mais do que mil palavras").

Essa discussão se soma à crítica feita por Stuart Hall (2003) ao modelo tradicional de comunicação em relação ao papel que os espectadores ocupam nessa dinâmica comunicacional. Em geral, os estudos e os usos educativos de vídeos pressupõem uma passividade dos alunos espectadores diante do audiovisual, cabendo a esses espectadores a simples aceitação e a passiva assimilação dos conteúdos transmitidos. Na esfera mais ampla dos estudos de sociologia e de comunicação, Hall critica a compreensão do modelo tradicional de comunicação sobre as relações de poder entre emissores e receptores/espectadores, considerando tal modelo de viés positivista e behaviorista por tratar a comunicação como um processo unilinear e unidirecional que enfatiza a transmissão da mensagem. Sob essa perspectiva as características das mensagens prescreveriam os efeitos que seriam produzidos na audiência.

Diante da recorrência do uso de vídeos e filmes na Educação Médica, buscou-se neste artigo fazer uma revisão de literatura da produção acadêmica sobre os usos e apropriações dos audiovisuais a fim de investigar como a área tem se apropriado desses recursos, sob que concepções e no contexto de que disciplinas isso se dá. 


\section{METODOLOGIA}

Uma pesquisa bibliográfica pode ser feita com a delimitação por artigos em periódicos, trabalhos em anais de eventos, dissertações e teses etc. Para os objetivos desta pesquisa, delimitou-se como universo de investigação apenas periódicos que estivessem na base de dados do WebQualis ${ }^{5}$ na área de medicina, ensino ou educação, nos estratos A1, A2, B1 e B2 em uma dessas áreas. Sob esse critério, foram selecionados quatro periódicos: (1) Medical Education; (2) Educación Médica Superior; (3) Revista Brasileira de Educação Médica; (4) BMC Medical Education. O corpus da pesquisa foi definido pela busca de trabalhos publicados nos últimos dez anos, e, como esse levantamento foi realizado em 2014, o período corresponde de 2004 a 2013.

As buscas foram realizadas por meio das palavras-chave vídeo, filme e cinema, quando necessário traduzidas no idioma nativo da revista. Na revista Medical Education, o sistema de busca retornou trabalhos que contavam com coleta de dados por meio de gravação em vídeo, e, buscando o refinamento da busca, se acrescentou o termo educational ao termo video. A revista cubana Educación Médica Superior não contava com sistema de busca por palavras-chave, e, por esse motivo, foi preciso realizar a busca a partir da leitura dos títulos e resumos dos trabalhos. Esse procedimento também foi adotado, em um segundo momento, nas demais revistas.

A revista Medical Education retornou uma quantidade expressiva de artigos (em torno de mil), e eliminamos todos em que o audiovisual fosse o objeto da pesquisa e/ou não fosse usado como recurso educativo. Também excluímos trabalhos que estivessem apenas publicados em forma de resumo e que não estivessem disponíveis para a leitura a partir do Portal de Periódicos da Capes $^{6}$. Dessa forma, a busca nessa revista resultou em quatro artigos, que foi reduzida a três após a leitura completa dos mesmos. A busca na revista BMC Medical Education retornou 80 artigos, dos quais apenas sete atendiam aos critérios de exclusão e inclusão, utilizados para todos os periódicos. Na Revista Brasileira de Educação Médica, dos sete resultados iniciais, apenas um foi excluído. A busca no periódico Educación Médica Superior apresentou, inicialmente, seis trabalhos, dos quais três foram excluídos.

5 Disponível em: <http://qualis.capes.gov.br/>.

6 Mesmo conectados via Portal de Periódicos da Capes, muitos trabalhos dependiam de pagamento para leitura. 
No Quadro 1 apresentamos os quatro periódicos, que doravante serão referenciados por meio de seus códigos, os termos de busca e o número de artigos retornados.

\section{Quadro 1 - Periódicos selecionados para revisão de literatura}

\begin{tabular}{|c|c|c|c|c|c|}
\hline PERIÓDICO & CÓDIGO & PAÍS & QUALIS & $\begin{array}{c}\text { TERMOS DE } \\
\text { BUSCA } \\
\end{array}$ & ARTIGOS \\
\hline Medical Education & ME & $\begin{array}{l}\text { Reino } \\
\text { Unido }\end{array}$ & $\begin{array}{l}\text { A1 Ensino } \\
\text { A2 Medicina }\end{array}$ & $\begin{array}{c}\text { educational } \\
\text { video; film; movie; } \\
\text { movies; cinema }\end{array}$ & 3 \\
\hline Educación Médica Superior & EMS & Cuba & A1 Ensino & - & 3 \\
\hline BMC Medical Education & $\mathrm{BMC}$ & $\begin{array}{l}\text { Reino } \\
\text { Unido }\end{array}$ & $\begin{array}{l}\text { B2 Ensino } \\
\text { B4 Educação } \\
\text { B2 Medicina }\end{array}$ & $\begin{array}{l}\text { video; film; } \\
\text { movie; movies; } \\
\text { cinema }\end{array}$ & 7 \\
\hline $\begin{array}{l}\text { Revista Brasileira de } \\
\text { Educação Médica }\end{array}$ & RBEM & Brasil & $\begin{array}{l}\text { A2 Ensino } \\
\text { B3 Educação } \\
\text { B4 Medicina }\end{array}$ & $\begin{array}{l}\text { vídeo; filme; } \\
\text { cinema }\end{array}$ & 5 \\
\hline \multicolumn{5}{|c|}{ TOTAL DE ARTIGOS } & 18 \\
\hline
\end{tabular}

Fonte: Elaborado pelos autores

\section{RESULTADOS E DISCUSSÃO}

Nos 18 artigos que constituem o corpus dessa pesquisa (Quadro 2), buscamos atentar às seguintes questões: (1) Consistem em que tipo de estudo? (2) Que concepções trazem sobre vídeos e filmes e seus usos na educação? (3) Como o vídeo é pesquisado? (4) O uso/estudo se relaciona a que disciplina da medicina? 
Quadro 2 - Título, ano de publicação, autoria, tipo de estudo e periódico dos artigos

\begin{tabular}{|c|c|c|c|c|c|}
\hline ARTIGO & TÍTULO & ANO & AUTORIA & ESTUDO & PERIÓD. \\
\hline $\mathbf{A}$ & $\begin{array}{l}\text { Comparison of text and video } \\
\text { cases in a postgraduate } \\
\text { problem-based learning } \\
\text { format }\end{array}$ & 2005 & $\begin{array}{l}\text { Balsley et } \\
\text { al. }\end{array}$ & empírico & \multirow{3}{*}{$\mathrm{ME}$} \\
\hline B & $\begin{array}{l}\text { How video cases should be } \\
\text { used as authentic stimuli in } \\
\text { problem-based medical } \\
\text { education }\end{array}$ & 2007 & $\begin{array}{l}\text { De Leng et } \\
\text { al. }\end{array}$ & empírico & \\
\hline $\mathbf{C}$ & $\begin{array}{l}\text { Video-based cases disrupt } \\
\text { deep critical thinking in } \\
\text { problem-based learning }\end{array}$ & 2012 & $\begin{array}{l}\text { Roy e } \\
\text { McMahon }\end{array}$ & empírico & \\
\hline D & $\begin{array}{l}\text { El video como medio de } \\
\text { enseñanza: Universidad Barrio } \\
\text { Adentro. República } \\
\text { Bolivariana de Venezuela }\end{array}$ & 2007 & $\begin{array}{l}\text { Valdivia, } \\
\text { Mansolo e } \\
\text { Medina }\end{array}$ & teórico & \multirow{3}{*}{ EMS } \\
\hline $\mathbf{E}$ & $\begin{array}{l}\text { Utilización de videos } \\
\text { didácticos como innovación } \\
\text { en la enseñ. de la toxicología }\end{array}$ & 2009 & $\begin{array}{l}\text { Tremarias e } \\
\text { Velásquez }\end{array}$ & empírico & \\
\hline $\mathbf{F}$ & $\begin{array}{l}\text { Modelo comunicacional para } \\
\text { las videoclases en las ciencias } \\
\text { básicas biomédicas }\end{array}$ & 2011 & Cavero & empírico & \\
\hline $\mathbf{G}$ & $\begin{array}{l}\text { Using television shows to } \\
\text { teach communication skills in } \\
\text { internal medicine residency }\end{array}$ & 2009 & Wong et al. & empírico & \multirow{4}{*}{$\mathrm{BMC}$} \\
\hline $\mathbf{H}$ & $\begin{array}{l}\text { Developing counseling skills } \\
\text { through pre-recorded videos } \\
\text { and role play: a pre- and post- } \\
\text { intervention study in a } \\
\text { Pakistani medical school }\end{array}$ & 2010 & Ahsen et al. & empírico & \\
\hline I & $\begin{array}{l}\text { Using movies to teach } \\
\text { professionalism to medical } \\
\text { students }\end{array}$ & 2011 & $\begin{array}{l}\text { Klemenc- } \\
\text { Ketis e } \\
\text { Kersnik }\end{array}$ & empírico & \\
\hline $\mathbf{J}$ & $\begin{array}{l}\text { Australian medical students' } \\
\text { perceptions of professionalism } \\
\text { and ethics in medical } \\
\text { television programs }\end{array}$ & 2011 & $\begin{array}{l}\text { Weaver e } \\
\text { Wilson }\end{array}$ & empírico & \\
\hline
\end{tabular}




\begin{tabular}{|c|c|c|c|c|c|}
\hline $\mathbf{K}$ & $\begin{array}{l}\text { Nervous system examination } \\
\text { on YouTube }\end{array}$ & 2012 & Azer et al. & teórico & \\
\hline $\mathbf{L}$ & $\begin{array}{l}\text { Towards a conceptual } \\
\text { framework demonstrating the } \\
\text { effectiveness of audiovisual } \\
\text { patient descriptions (patient } \\
\text { video cases): a review of the } \\
\text { current literature }\end{array}$ & 2012 & $\begin{array}{l}\text { Roland, } \\
\text { Coats e } \\
\text { Matheson }\end{array}$ & teórico & \\
\hline M & $\begin{array}{l}\text { Cinema in the training of } \\
\text { psychiatry residents: focus on } \\
\text { helping relationships }\end{array}$ & 2013 & $\begin{array}{l}\text { Gramaglia } \\
\text { et al. }\end{array}$ & teórico & \\
\hline $\mathbf{N}$ & $\begin{array}{l}\text { Cinema para o estudante de } \\
\text { medicina: um recurso } \\
\text { afetivo/efetivo na educação } \\
\text { humanística }\end{array}$ & 2005 & Blasco et al. & teórico & \multirow{5}{*}{ RBEM } \\
\hline $\mathbf{O}$ & $\begin{array}{l}\text { O cinema e a educação } \\
\text { bioética no curso de } \\
\text { graduação em Medicina }\end{array}$ & 2011 & $\begin{array}{l}\text { Cezar, } \\
\text { Gomes e } \\
\text { Siqueira- } \\
\text { Batista }\end{array}$ & teórico & \\
\hline $\mathbf{P}$ & $\begin{array}{l}\text { O cinema como instrumento } \\
\text { didático para a abordagem de } \\
\text { problemas bioéticos: uma } \\
\text { reflexão sobre a eutanásia }\end{array}$ & 2011 & $\begin{array}{l}\text { Dantas, } \\
\text { Martins e } \\
\text { Militão }\end{array}$ & teórico & \\
\hline $\mathbf{Q}$ & $\begin{array}{l}\text { Videoaula ou teleconsultoria } \\
\text { no aprendizado em } \\
\text { otorrinolaringologia do } \\
\text { médico de família }\end{array}$ & 2012 & $\begin{array}{l}\text { Oliveira e } \\
\text { Gonçalves }\end{array}$ & empírico & \\
\hline $\mathbf{R}$ & $\begin{array}{l}\text { Recepção audiovisual na } \\
\text { educação médica: leituras de } \\
\text { um vídeo educativo de } \\
\text { psicologia médica por } \\
\text { estudantes de medicina }\end{array}$ & 2012 & $\begin{array}{l}\text { Pastor } \\
\text { Junior, } \\
\text { Rezende e } \\
\text { Bastos }\end{array}$ & empírico & \\
\hline
\end{tabular}

Fonte: Elaborado pelos autores

É interessante notar que dos 18 artigos, 14 foram produzidos nos últimos cinco anos, dos quais 11 nos últimos três anos, evidenciando a relevância da presente revisão, já que parece haver uma tendência no aumento da produção acadêmica sobre essa temática a despeito dos artigos não disponíveis para a leitura gratuita via Portal de Periódicos da Capes (um dos limites desta pesquisa), no caso do periódico ME. 


\subsection{Medical Education}

Os artigos A de autoria de Balsley et al. (2005), B de autoria de De Leng et al. (2007) e C de autoria de Roy e McMahon (2012) apresentam fundamentação e discussão de dados empíricos e todos consistem em investigação sobre o uso de casos médicos em vídeos e textos para o treinamento do raciocínio clínico dos estudantes nos períodos pré-clínica, ou seja, antes da parte preponderantemente prática da formação médica. Esses estudos foram feitos em aulas orientadas pela "aprendizagem baseada em problemas" (PBL - Problem Based Learning).

$\mathrm{O}$ artigo A cita $\mathrm{B}$, chegando a se assemelharem, uma vez que compartilham objetivos comparar a efetividade do uso de casos clínicos dispostos em textos ou em vídeos como recursos pedagógicos para o "treinamento" do raciocínio clínico - e grande parte dos referenciais teóricos e procedimentos metodológicos. Os dados são produzidos a partir de observação das exibições e das discussões em grupo subsequentes à exibição dos vídeos. Os resultados indicam que os estudantes analisam e discutem por mais tempo quando se faz uso de vídeos. Segundo Balsley et al. (2005), por apresentarem visualmente os sintomas, os vídeos estimularam processos cognitivos, o que aumentou a capacidade de uso da memória para análise dos casos clínicos. Já para De Leng et al. (2007), os vídeos proporcionaram representações mais realísticas, ilustrações mais autênticas e compreensíveis. Para os autores desses artigos os vídeos foram mais motivadores e desafiadores e de mais fácil memorização para os estudantes, ao afirmarem que os vídeos podem fornecer uma imagem mais holística dos problemas dos pacientes, transmitir emoções, linguagem corporal e outras não-verbais, mais direta e vividamente ao fazer uso de uma linguagem mais familiar à geração X (DE LENG et al., 2007).

No artigo $\mathrm{C}$, videocasos foram estudados em relação à percepção de aspectos psicossociais de pacientes. Nesse trabalho parte-se de fundamentação semelhante a dos anteriores, contudo chega-se a resultados distintos. Segundo os autores, os vídeos provocaram maior satisfação nos estudantes, mas estiveram associados a uma sensível redução do pensamento crítico sobre os temas abordados, talvez devido a maior complexidade provocada pela combinação de áudio e vídeo, além da maior carga psicossocial e emocional, inibindo a capacidade de formular hipóteses. Com isso, Roy e McMahon (2012) acreditam que o excesso de informação talvez tenha distraído mais os estudantes, questionando, assim, os resultados encontrados em A e B, e ponderam que respostas emotivas e engajamento dos estudantes não 
foram mensurados, sugerindo que outros estudos se voltem a tal caracterização. Terminam afirmando que o uso de vídeos não é uma panaceia na educação, e que esse uso deve ser feito com muitas precauções.

Nesses três trabalhos, os vídeos eram recursos de observação dos pacientes para produção de um raciocínio clínico. Todos partiram do pressuposto de que o vídeo teria um poder de comunicação superior ao texto por supostamente transmitir mais informações e detalhes dos pacientes, sendo que nos dois primeiros se concluiu que esse maior poder aprimorou a cognição dos estudantes, e no terceiro foi um obstáculo ao exercício do raciocínio clínico.

\subsection{Educación Médica Superior}

No periódico EMS encontramos um estudo teórico e dois empíricos. No artigo D, Valdivia, Mansolo e Medina (2007) partem de uma revisão de literatura e apresentam propostas para a utilização de vídeos na formação médica cubana. Os dois estudos empíricos se voltam ao ensino de toxicologia no contexto da formação em medicina da família. Nesse artigo, o vídeo é entendido como um recurso que possibilita a apropriação de conteúdos de maneira reflexiva e consciente, e seria, portanto, bastante apropriado para a utilização na formação de médicos comunitários. Segundo seus autores, o vídeo seria um meio de divulgação massiva, direcionado a um público homogêneo, combina elementos de outros meios e favorecem o desenvolvimento de processos de ensino-aprendizagem e a percepção de eventos, característica essa que também homogeneizaria os estudantes espectadores por apagar suas diferenças. A construção dessa homogeneização, para os autores, estaria de acordo com os pressupostos norteadores da medicina comunitária, e o papel do professor seria o de mediador, buscando romper com a passividade dos estudantes.

No artigo E, de autoria de Tremarias e Velásquez (2009), é avaliada a utilidade de vídeos como estratégia de ensino de toxicologia no curso de medicina. Para isso, foram exibidos três vídeos sobre a ação das drogas no cérebro humano e aplicados questionários tipo pré e pós-teste. Os autores afirmam que os vídeos facilitam a aquisição de conteúdos científicos pelos estudantes, estimulam a atenção e participação e são mais eficientes do que aulas expositivas, porém produzem aprendizagem menos complexa. Nota-se que a conceituação do vídeo é desencontrada dos resultados, uma vez que os autores baseiam-se na 
ideia de que o vídeo motiva, estimula atenção e participação, mas o desenho metodológico permitiu apenas avaliar o quanto os estudantes aprenderam, se a aprendizagem foi melhor ou pior, algo relativamente comum em pesquisas que têm o uso de vídeos como objeto de pesquisa.

Em F, Cavero (2011) analisou a utilização de videoclasses, os papeis dos participantes (professor do vídeo, professor da classe e estudantes) e suas interações. O autor caracteriza videoclasse como aulas e/ou palestras gravadas em vídeo que são exibidas e discutidas. Para isso haveria o professor da videoclasse e o professor da classe que mediaria a discussão após a exibição do vídeo. Segundo o autor, essa ideia está de acordo com a formação de médicos em larga escala ao romper a barreira tempo/espaço com a transmissão da aula gravada de um professor. Ele afirma também que a mediação da discussão após a exibição do vídeo tem papel fundamental, pois seria esse o "verdadeiro" momento em que se produziriam reflexões: o vídeo, transporte dos conteúdos, deveria ser contextualizado, ter sua relevância sublinhada pelo mediador que buscaria construir as conexões entre o vídeo e os estudantes. Chama atenção a ideia do vídeo como aula pronta, teletransportável, e que seria a discussão após a exibição a principal parte do evento educativo no qual o vídeo se insere.

Esses artigos evidenciam um superdimensionamento das potencialidades do vídeo quanto aos pressupostos que sustentam seus estudos, mesmo que suas conclusões não se aproximem da discussão sobre tais afirmações.

\subsection{BMC Medical Education}

Quatro dos sete trabalhos publicados na BMC são estudos empíricos, e a maior parte se volta à compreensão da contribuição do uso de audiovisuais na formação médica para a comunicação entre médico e paciente. Nos artigos G de autoria de Wong et al. (2009), H de autoria de Ahsen et al. (2010) e I de autoria de Klemenc-Ketis e Kersnik (2011), essa compreensão é pautada por atitudes e valores humanistas, tal como a empatia. Os autores de G e H pesquisaram especificamente como o uso de filmes e vídeos pode contribuir para a melhora da comunicação médico-paciente de, respectivamente, residentes e graduandos do $4^{\circ}$ ano. Wong et al. (2009) aplicaram um questionário antes e após a realização de uma apresentação sobre um modelo de comunicação médico-paciente, seguido pela exibição de cenas das séries de TV House e Grey's Anatomy. O questionário, no entanto, não avaliava o que foi aprendido a partir da atividade, mas o que e como os estudantes julgavam ter 
aprendido. Os resultados indicaram que os estudantes acreditaram ter aprendido melhor por conta da contribuição das cenas ao exemplificarem ações desejadas na comunicação médico paciente. Os autores baseiam-se na ideia de que audiovisuais são ferramentas efetivas que melhoram o ensino justamente por oferecerem uma melhor descrição (mais dinâmica e humanizada) de situações clínicas e, em decorrência disso, atuariam também motivando e engajando os estudantes em vivências emocionais na exibição.

Sustentação bastante similar encontra-se em H, em que Ahsen et al. (2010) consideram ainda que os vídeos poderiam atuar especificamente no treinamento de habilidades de comunicação. Nesse estudo, encenações de atendimento médico foram acompanhadas por exibição de vídeos (produzidos no contexto de realização da pesquisa) que se voltavam a apresentar elementos essenciais da comunicação médico-paciente, como: formas de iniciar uma consulta, uso de perguntas abertas e fechadas em uma consulta, clarificações, facilitações e acesso às concepções dos pacientes. Questionários pré e pós-teste evidenciaram, segundo os autores, considerável melhora no entendimento dos estudantes sobre os elementos essenciais de comunicação. Contudo, essa melhora não se repetiu na prática real com os pacientes, uma vez que não resultaram em efetiva mudança no período de realização do estudo com os estudantes.

No artigo I, Klemenc-Ketis e Kersnik (2011) tiveram como objetivo avaliar a relevância e utilidade do uso de filmes para ensinar profissionalismo e medir o impacto desse uso nas atitudes de estudantes do $4^{\circ}$ ano de Medicina. O conceito de profissionalismo, segundo os autores, diz respeito à coleção de atitudes, valores, comportamento e relações que atuam como fundamentos do contrato dos profissionais de saúde com a sociedade, aspectos que geralmente apenas figuram no currículo oculto. Nesse estudo, os filmes foram compreendidos sob uma suposta possibilidade de controle de cenário da prática médica, ao apresentar o contexto de vida mais amplo dos pacientes e facilitar a educação sobre aspectos psicossociais no cuidado à saúde. É interessante notar que os resultados do estudo reforçam a contribuição do filme comercial de longa-metragem exibido (Uma lição de vida, 2001) para o reconhecimento de questões como comunicação, empatia, interesses pessoais intervenientes na prática médica, cuidados paliativos e as fases da morte de um paciente terminal. Segundo os autores, tal filme também teria disparado uma reflexão a respeito da própria existência dos estudantes, fazendo-os repensar sobre a vida e a morte. Apesar de objetivar o ensino do conceito de profissionalismo, as questões abordadas em I com o uso do filme são bastante 
próximas das abordadas nos artigos $\mathrm{G}$ e $\mathrm{H}$, voltados à comunicação médico-paciente. Esses três trabalhos também se aproximam em sua fundamentação teórica sobre a relação entre audiovisual e educação e nos tipos de estudos realizados.

Os autores do artigo J, Weaver e Wilson (2011), também compartilham dessa sustentação teórica no desenho do estudo, e, além disso, destacam que os programas médicos de TV (filmes e séries) oferecem aos estudantes representações sobre a carreira escolhida e que poderiam ser utilizados como recursos na futura prática médica desempenhada. $\mathrm{O}$ foco desse estudo foi caracterizar as percepções dos estudantes a respeito de profissionalismo e ética mediante a audiência das séries de TV House, Scrubs e Grey's Anatomy. Os autores identificaram bons e maus exemplos de condutas médicas nas séries e, apesar de considerarem que a discussão desses programas contribuiria para o desenvolvimento da percepção crítica por parte dos estudantes, afirmaram não estarem seguros sobre isso.

Em K, Azer et al. (2012) trazem o resultado de uma busca por vídeos no YouTube que abordem o sistema nervoso e esses são caracterizados segundo conteúdos, técnicas audiovisuais e características pedagógicas. O trabalho parte de uma compreensão de que os vídeos seriam recursos pedagógicos centrados nos alunos, valorizando sua autonomia. Como resultados, pouco mais da metade dos vídeos poderiam ser utilizados para propósitos educativos, e os autores ponderaram que eles ofereciam a vantagem de explicar conceitos difíceis ao trazerem simulações, diagramas, animações, analogias e pacientes simulados. Ao final, indicaram que o aprendizado poderia ser melhorado se os vídeos fossem mais bem planejados, explorassem corretamente os conceitos, devendo ser apresentados de forma clara e adequada.

No artigo L, Roland, Coats e Matheson (2012) apresentam quase uma meta-análise de trabalhos que estudam o uso de videocasos na formação em Medicina. Porém, esse trabalho não pode ser considerado exatamente como uma meta-análise, pois pretende mais especificamente avaliar a validade interna dos estudos que se voltaram a pesquisar o uso de videocasos, que, segundo um entendimento encontrado na literatura, produziriam aprimoramento do processamento cognitivo, afirmações rechaçadas pelos autores desse artigo. Assim, os autores desse artigo questionaram a validade dos resultados encontrados em nos artigos A e B (que fazem parte do corpus da presente revisão).

No estudo apresentado em M, desenvolvido em uma cadeira de psiquiatria, Gramaglia et al. (2013) apresentam uma sustentação teórica marcada pela perspectiva analítica 
psicológica de Jung (segundo a qual, resumidamente, as imagens poderiam evocar emoções e ativar complexos inconscientes). Seus autores reconhecem que os filmes têm potencial para atuar na formação de empatia e habilidade relacionais, além de provocar debates sobre tópicos que não são usualmente abordados na formação médica. $\mathrm{O}$ estudo se volta a analisar quatro filmes que oferecem a oportunidade de reflexão sobre o significado de estar envolvido em uma relação de cuidado. Os autores apresentam análises dos filmes com possibilidades de discussão, e chegam a conclusões próximas das ideias que fundamentaram seu estudo.

Os trabalhos do periódico BMC mostraram uma tendência a compreenderem os audiovisuais como forma de "reprodução" de uma realidade da prática médica que ainda não seria "experienciada" com frequência pelos estudantes (a maior parte dos estudos se deu no $4^{\circ}$ ano de Medicina ou no princípio do período de residência médica). Essa apresentação do ambiente da prática médica pelos filmes ocorreria de maneira ampliada e também envolveria o contexto mais amplo da vida do paciente e dos médicos, o que facilitaria a percepção da dimensão psicossocial. De maneira geral, os artigos se dedicaram à comunicação médicopaciente, RMP, condutas éticas e atitudes profissionais adequadas. As disciplinas foram, em geral, as de clínica médica ou correlatas, o que expressa uma coerência entre os usos propostos para os audiovisuais e as finalidades das disciplinas, já que eles apresentam situações que ilustrariam a prática médica real.

\subsection{Revista Brasileira de Educação Médica}

Dos cinco artigos da RBEM, três são discussões teóricas com proposições sobre as potencialidades de filmes e suas possibilidades de uso na formação médica. Encontram-se nessa categoria os artigos N de Blasco et al. (2005), O de Cezar, Gomes e Siqueira-Batista (2011) e P de Dantas, Martins e Militão (2011), e esses dois últimos utilizam largamente na fundamentação trabalhos anteriores produzidos por um dos autores do artigo N. Nesses três trabalhos, os filmes são considerados obras de arte que teriam a vantagem de suscitar emoções. Enquanto em N emoção é considerada "porta de entrada" para uma formação mais humana dos profissionais de medicina, para os autores de $\mathrm{O}$ e $\mathrm{P}$ emoções geradas a partir dos filmes despertariam reflexões que atuariam na formação em Bioética. Em $\mathrm{N}$ não há relação entre o uso de filmes e uma disciplina específica, relatando-se superficialmente algumas experiências em disciplinas eletivas voltadas à formação artística no curso de Medicina. Nesse 
trabalho há referências de trabalhos anteriores de um dos autores que investigaram o uso de filmes na disciplina Medicina de Família.

Nesses três trabalhos encontra-se a ideia de que os filmes seriam meios de sensibilizar, pois inicialmente não passariam pela dimensão da razão, produzindo reflexões que suscitariam valores e atitudes adequadas nos estudantes. Segundo os autores, essa característica dos filmes possibilitaria a vivência de experiências que nem todos os estudantes podem dispor em sua formação. $\mathrm{O}$ audiovisual, como legítimo recurso para a formação de atitudes humanizadas em Medicina, provocaria emoções que deveriam ser objeto de reflexão dos alunos após a exibição. Nos três trabalhos afirma-se que as reflexões a partir de grupos de discussão oportunizariam o estabelecimento de identificações dos estudantes com os personagens apresentados nos filmes e questionamentos sobre o universo fílmico que levariam a uma discussão da própria realidade na qual estes estudantes estão localizados.

Discutir o filme levaria, em um segundo momento, a discutir seu cotidiano de práticas (CEZAR; GOMES; SIQUEIRA-BATISTA, 2011). Os filmes teriam a capacidade de mobilizar o cotidiano do estudante e os trazer para a sala de aula (DANTAS; MARTINS; MILITÃO, 2011). Seria justamente nesse ponto que os filmes também seriam importantes recursos de contextualização dos conhecimentos desenvolvidos nas disciplinas que se voltem à humanização das práticas médicas. Blasco et al. (2005) caracterizam os espectadores, estudantes de medicina, como pertencentes a uma geração que desenvolve um consumo alienado de imagens, a sociedade do espetáculo, que consistiria no fato da imagem sobrepor o pensamento, ou seja, o que é meramente "estético" seria consumido sem a devida reflexão crítica. De antemão já podemos destacar que essa afirmação é um tanto problemática, pois parece supor que as imagens não são também produzidas e investidas de pensamento.

Os três estudos recomendam discussão após a exibição dos filmes, um momento de elaboração das sensações/sentimentos suscitados pelos filmes, de reflexão e de interpretação, que seria o momento de fato de produção de saberes. Há também recomendações de filmes comerciais para discussão em aula de temas como eutanásia, bioética, ética médica, relação médico-paciente, entre outros. Apesar de aparentemente serem bastante potentes, as afirmações contidas nesses três artigos não trazem qualquer sustentação empírica, consistindo em discussões teóricas que mobilizam outros trabalhos sem também indicar nesses qualquer base empírica para suas afirmações. 
Finalmente, os artigos Q de autoria de Oliveira e Gonçalves (2012) e R de autoria de Pastor Junior, Rezende e Bastos (2012) são estudos empíricos. O primeiro é um estudo comparativo entre o uso de videoaulas e teleconsultorias (consultorias via fóruns de discussão em plataformas de educação a distância). Este estudo consistiu na aplicação de questionários a dois grupos de estudantes de Otorrinolaringologia para avaliar seu aprendizado sobre a parte clínica. Os resultados indicaram que a turma que estudou por videoaulas adquiriu com maior eficiência as teorias. Entretanto, nenhum dos dois métodos apresentou mudança significativa na prática clínica dos estudantes. De posse desses resultados, os autores fizeram uma consideração a respeito de videoaulas, relacionando-as com resultados de outros trabalhos ao afirmarem que tal recurso agregou conhecimento teórico, mas não modificou a prática. Nesse trabalho, o vídeo é compreendido como tecnologia de transmissão/armazenamento de conteúdo e seu uso educativo buscaria exatamente superar obstáculos impostos pelo tempo e espaço no processo de ensino-aprendizagem.

O artigo R, Pastor Junior, Rezende e Bastos (2012), é um trabalho de nosso grupo de pesquisa como produção da dissertação de mestrado do primeiro autor, e, por isso, compartilha boa parte dos referenciais teórico-metodológicos com a presente revisão de literatura. Trata-se de um estudo holístico com a análise de um vídeo educativo que trata da temática da humanização da prática médica (sobretudo as pertinentes à RMP), entrevistas com seus produtores e análise dos sentidos produzidos por estudantes ao assistirem ao vídeo na disciplina Psicologia Médica, almejando caracterizar a negociação que ocorre entre as intenções dos produtores do vídeo e as leituras dos espectadores. O artigo se apoia nos estudos culturais ao compreender os filmes e vídeos como carregados de artifícios para tentar predizer/prescrever os sentidos produzidos pelos espectadores, contudo, conforme indicaram os resultados, os espectadores dispõem de relativa autonomia e nem sempre seguem tais prescrições uma vez que são ativos nessa produção de sentidos e não meros receptores passivos dos conteúdos presentes nos vídeos.

Com isso, é possível afirmar que a maior parte dos trabalhos da RBEM que se dedica a estudar o uso de vídeos e filmes na Educação Médica realiza seus estudos no contexto de disciplinas que se voltam à humanização da prática médica, sobretudo as disciplinas de bioética. Eles tendem a compreender os filmes como obras de arte que, a partir da fruição estética, utilizariam de "canais da emoção" como atalhos à atividade reflexiva a respeito dos temas abordados pelos filmes, ideia defendida principalmente pelos autores dos artigos $\mathrm{N}, \mathrm{O}$ e 
P. Por outro lado, os autores dos artigos Q e R se aproximam mais de uma compreensão dos filmes e vídeos como mediadores socioculturais, buscando caracterizar e avaliar seus usos em sala de aula.

\section{CONSIDERAÇÕES FINAIS}

A presente revisão identificou algumas tendências. Os trabalhos que se referiam a uso de filmes, em geral, os tomavam como um recurso que seria capaz de possibilitar o surgimento de emoções ou reflexões que facilitariam o aprendizado dos conceitos nas obras apresentadas. Estes usos se deram de maneira majoritariamente contextualizados, em que os filmes se voltavam a formar para habilidades relacionais, atitudes, comunicação médicopaciente e condutas éticas nas disciplinas de clínica médica, preparatórias para estágios e residências médicas, ou disciplinas voltadas ao profissionalismo médico. Quando não, os trabalhos se referiam ao uso de vídeos, em geral de videocasos ou de imagens de sintomas para que os alunos de alguma forma exercitassem o raciocínio diagnóstico. Nesses casos, os vídeos teriam o papel de reproduzir fragmentos da realidade como alternativa à possibilidade de visualização direta desses sintomas. Os vídeos também foram estudados como possibilidade do estudante observar como se desenvolve uma situação real de comunicação médico-paciente.

Tanto vídeos como filmes tenderam a ter sua utilidade justificada pelas contribuições que trariam às aulas pela linguagem que seria mais próxima à geração dos estudantes, por permitirem a formação em localidades mais distantes e por possibilitarem a percepção de aspectos não tão facilmente percebidos na realidade da prática médica.

Os artigos considerados como estudos teóricos apresentam revisão de literatura, avaliação de obras audiovisuais e/ou de propostas de atividades. No entanto, a maior parte deles traz uma coleção de pressuposições que não foram objetos de pesquisas empíricas, consistindo em uma reflexão baseada em outras produções que buscavam justificar o uso de filmes e vídeos na educação médica, fato mais observado no periódico nacional. Dentre os trabalhos teóricos, chama atenção o trabalho de Roland, Coats e Matheson (2012) que identificou inconsistências na validade interna de estudos empíricos sobre o uso de videocasos, explicitando relativa incipiência dos trabalhos analisados. 
Em se tratando dos estudos empíricos, alguns trabalhos são comparações entre algum método e o uso de vídeos, e suas conclusões não são tão fortes para afirmar algo específico sobre a natureza do uso dos vídeos na educação. Outros estudos fizeram uso de questionários antes e depois da exibição de um vídeo ou filme, considerando apenas o que ocorria imediatamente após a exibição. Boa parte desses trabalhos voltava-se à formação de habilidades, atitudes, valores e competências de raciocínio clínico.

Os potenciais e vantagens conferidos aos audiovisuais carecem de mais estudo, tanto teoricamente quanto empiricamente. Como alternativa, os estudos holísticos de recepção audiovisual se preocupam em atender demandas teórico-metodológicas ao considerar tanto as obras audiovisuais (filmes e vídeos), o cotidiano de formação no qual eles se inserem, bem como as leituras e saberes produzidos por estudantes a partir do uso de audiovisuais.

\section{REFERÊNCIAS}

AHSEN, N. F.; BATUL, S. A.; AHMED, A. N.; IMAM, S. Z.; IQBAL, H.; SHAMSHAIR, K.; ALI, H. Developing counseling skills through pre-recorded videos and role play: a pre- and post-intervention study in a Pakistani medical school. BMC Medical Education, v.10, n.7, 2010.

ALMEIDA, M. J.; CAMPOS, J. J. B.; TURINI, B.; NICOLETTO, S. C. S.; PEREIRA, L. A.; REZENDE, L. R.; MELLO, P. L. Implantação das Diretrizes Curriculares Nacionais na graduação em Medicina no Paraná. Revista Brasileira de Educação Médica, v.31, n.2, p.156$165,2007$.

ARROIO, A.; GIORDAN, M. O vídeo educativo: aspectos da organização do ensino. Química Nova na Escola, v. 24, p.8-11, 2006.

AZER, S. A.; ALESHAIWI, S. M.; ALGRAIN, H. A.; ALKHELAIF, R. A. Nervous system examination on YouTube. BMC Medical Education, v.12, n.126, 2012.

BALSLEV, T.; DE GRAVE, W. S.; MUIJTJENS, A. M.; SCHERPBIER, A. J. J. A. Comparison of text and video cases in a postgraduate problem-based learning format. Medical Education, v.39, n.11, p.1086-1092, 2005.

BLASCO, P. G.; GALLIAN, D. M. C.; RONCOLETTA, A. F. T.; MORETO, G. Cinema para o estudante de medicina: um recurso afetivo/efetivo na educação humanística. Revista Brasileira de Educação Médica, v.29, n.2, p.119-128, 2005.

CAVERO, J. S. D. Modelo comunicacional para las videoclases en las ciencias básicas biomédicas. Educación Médica Superior, v.25, n.1, p.49-57, 2011. 
CEZAR, P. H. N.; GOMES, A. P.; SIQUEIRA-BATISTA, R. O cinema e a educação bioética no curso de graduação em Medicina. Revista Brasileira de Educação Médica, v.35, n.1, p.93$101,2011$.

DANTAS, A. A.; MARTINS, C. H.; MILITÃO, M. S. R. O cinema como instrumento didático para a abordagem de problemas bioéticos: uma reflexão sobre a eutanásia. Revista Brasileira de Educação Médica, v.35, n.1, p.69-76, 2011.

DE LENG, B. A.; DOLMANS, D. H. J. M.; VAN DE WIEL, M. W. J.; MUIJTJENS, A. M.; VAN DER VLEUTEN, C. P. M. How video cases should be used as authentic stimuli in problem-based medical education Medical Education, v.41, n.2, p.181-188, 2007.

FERRÉS, J. Vídeo e Educação. Porto Alegre, RS: Artmed, 1996.

GRAMAGLIA, C.; JONA, A.; IMPERATORI, F.; TORRE, E.; ZEPPEGNO, P. Cinema in the training of psychiatry residents: focus on helping relationships. BMC Medical Education, v.13, n.90, 2013.

HALL, S. Reflexões sobre o modelo de Codificação/Decodificação (entrevista com Stuart Hall). In: SOVIK, L. (Org.) Da diáspora: identidades e mediações culturais. Belo Horizonte: Editora UFMG; Brasília, DF: Unesco, 2003. p.353-386.

HODGE, R.; KRESS, G. Social semiotics. Ithaca: Cornell Univ. Press, 1988.

KLEMENC-KETIS, Z. E.; KERSNIK, J. Using movies to teach professionalism to medical students. BMC Medical Education, v.11, n.60, 2011.

LAMPERT, J. B. Na transição paradigmática da educação médica: o que o paradigma da integralidade atende que o paradigma flexneriano deixou de lado. Cadernos ABEM, 2004.

OLIVEIRA, M. H.; GONÇALVES, D. U. Videoaula ou teleconsultoria no aprendizado em otorrinolaringologia do médico de família. Revista Brasileira de Educação Médica, v.36, n.4, p.524-535, 2012.

PAGLIOSA, F. L.; DA ROS, M. A. O relatório Flexner: para o bem e para o mal. Revista Brasileira de Educação Médica, v.32, n.4, p.492-499, 2008.

PASTOR JUNIOR, A. A.; REZENDE, L. A. C.; BASTOS, W. G. Recepção audiovisual na educação médica: leituras de um vídeo educativo de psicologia médica por estudantes de medicina. Revista Brasileira de Educação Médica, v.36, n.4, p.516-523, 2012.

PERIM, G. L.; ABDALLA, I. G.; AGUILAR-DA-SILVA, R. H.; LAMPERT, J. B.; STELLA, R. C. R.; COSTA, N. M. S. C. Desenvolvimento docente e a formação de médicos. Revista Brasileira de Educação Médica, v.33, supl.1, p.70-82, 2010.

ROLAND, D.; COATS, T.; MATHESON, D. Towards a conceptual framework demonstrating the effectiveness of audiovisual patient descriptions (patient video cases): a review of the current literature. BMC Medical Education, v.12, n.125, 2012. 
ROY, R. B.; MCMAHON, G. T. Video-based cases disrupt deep critical thinking in problembased learning. Medical Education, v.46, n.4, p.426-435, 2012.

SANTOS, J. L. F.; WESTPHAL, M. F. Práticas emergentes de um novo paradigma de saúde: o papel da universidade. Estudos Avançados, v.13, n.35, p.71-88, 1999.

TREMARIAS, M. D.; VELÁSQUEZ, T. N. Utilización de videos didácticos como innovación en la enseñanza de la toxicologia. Educación Médica Superior, v.23, n.3, 2009.

VALDIVIA, P. M.; MANSOLO, A. S.; MEDINA, M. H. El video como medio de enseñanza: Universidad Barrio Adentro. República Bolivariana de Venezuela. Educación Médica Superior, v.21, n.2, 2007.

WEAVER, R.; WILSON, I. Australian medical students' perceptions of professionalism and ethics in medical television programs. BMC Medical Education, v.11, n.50, 2011.

WONG, R. Y.; SABER, S. S.; MA, I.; ROBERTS, J. M. Using televison shows to teach communication skills in internal medicine residency. BMC Medical Education, v.9, n.9, 2009.

WORTH, S. The Uses of Film in Education and Communication. In: GROSS, L. (Ed.) Studying Visual Communication. Philadelphia: University of Pennsylvania Press, 1981. p.108133. 